\title{
Derivation of groundwater flow-paths based on semi-automatic extraction of lineaments from remote sensing data
}

\author{
U. Mallast ${ }^{1,2}$, R. Gloaguen ${ }^{2}$, S. Geyer ${ }^{1}$, T. Rödiger ${ }^{1}$, and C. Siebert ${ }^{1}$ \\ ${ }^{1}$ Department Catchment Hydrology, Helmholtz-Centre for Environmental Research (UFZ), 06120 Halle, Germany \\ ${ }^{2}$ Remote Sensing Group, Institute of Geology, Freiberg University of Mining and Technology, 09599 Freiberg, Germany
}

Received: 22 December 2010 - Published in Hydrol. Earth Syst. Sci. Discuss.: 28 January 2011

Revised: 17 August 2011 - Accepted: 21 August 2011 - Published: 25 August 2011

\begin{abstract}
In this paper we present a semi-automatic method to infer groundwater flow-paths based on the extraction of lineaments from digital elevation models. This method is especially adequate in remote and inaccessible areas where in-situ data are scarce. The combined method of linear filtering and object-based classification provides a lineament map with a high degree of accuracy. Subsequently, lineaments are differentiated into geological and morphological lineaments using auxiliary information and finally evaluated in terms of hydro-geological significance. Using the example of the western catchment of the Dead Sea (Israel/Palestine), the orientation and location of the differentiated lineaments are compared to characteristics of known structural features. We demonstrate that a strong correlation between lineaments and structural features exists. Using Euclidean distances between lineaments and wells provides an assessment criterion to evaluate the hydraulic significance of detected lineaments. Based on this analysis, we suggest that the statistical analysis of lineaments allows a delineation of flow-paths and thus significant information on groundwater movements. To validate the flow-paths we compare them to existing results of groundwater models that are based on well data.
\end{abstract}

\section{Introduction}

Information on groundwater are scarce in many parts of the world, particularly where they are essential for ensuring sustainable socio-economical and ecological growing of economies. This requires collecting data in remote or inac-

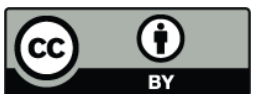

Correspondence to: U. Mallast (ulf.mallast@ufz.de) cessible areas where any a priori information on groundwater is beneficial. Planning adequately and time-effectively a field campaign and/or finding suitable sampling sites is also required. Nevertheless, while difficult to obtain, a priori information need to be reproducible, objective and reliable.

After Hobbs (1904) introduced the term lineament, it has been used in different fields (e.g. petrology, geology and hydrogeology) as indicator for remote structural interpretation of the respective areas of interest. O'Leary et al. (1976) define lineaments "as a mappable, simple or composite linear feature of a surface whose parts are aligned in a rectilinear or slightly curvilinear relationship and which differ from the pattern of adjacent features and presumably reflect some sub-surface phenomenon." In terms of groundwater, it is apparent that fractures and faults have surface expressions and thus can serve as indicator for water flow-paths (Anisimova and Koronovsky, 2007; Dinger et al., 2002; Fernandes and Rudolph, 2001; Meijerink et al., 2007). To prove the applicability of lineaments as indicators for either fault systems or assumable preferential groundwater flow-paths, many authors compared both features and revealed a strong correlation in shallow and deeper aquifers (Fernandes and Rudolph, 2001; Oguchi et al., 2003; Salvi, 1995; Sander et al., 1997).

Classical approaches to lineament extraction are conducted manually. Based on experience and expert knowledge they can be evaluated as objective but irreproducible and inefficient in terms of time and labour, especially when focused on a macroscale (Costa and Starkey, 2001; Hung et al., 2005; Sander, 2007; Vaz et al., 2008). Thus, in order to obtain reproducible and objective criterions as well as efficient procedures, automated and semi-automated algorithms (e.g. segment tracing algorithm (STA), Hough Transform, PCI LINE) were developed (Karnieli et al., 1996). Although being efficient, most of the automated algorithms seem to

Published by Copernicus Publications on behalf of the European Geosciences Union. 
be black boxes, where certain filtering or linking parameters need to be adjusted without visualizing intermediate results. This limits efficiency particularly for inexperienced user.

Methodically, semi-automatic and automatic approaches are based either on linear, non-linear and morphological spatial filters (Morris, 1991; Philip, 1996; Suzen and Toprak, 1998), edge tracing and linking methods (Fitton and Cox, 1998; Karnieli et al., 1996; Koike et al., 1995), or knowledge-based systems (Argialas and Mavrantza, 2004; Gloaguen et al., 2007; Marpu et al., 2008; Mavrantza and Argialas, 2006).

Inaccuracies emerge mostly from input data as multispectral or aerial images contain semantic linear features not originating from geological, but rather mainly from anthropogenic structures. To overcome this problem a largely manually conducted "correction-step" is introduced in many cases excluding non-geologic lineaments (Hung et al., 2005; Kocal et al., 2004).

By using digital elevation models (DEM), extracted lineaments solely rely on elevation information. Hence, only accounting for this aspect, DEMs represent a promising basis for semi-automatic lineament extraction for topographical, hydrological or geological purposes (e.g. Gloaguen et al., 2007; Jordan and Schott, 2005; Wladis, 1999).

For any purpose the ground sampling distance (GSD) of the DEMs plays an important role. Generally, the better the GSD of the DEM, the more topographical and groundwater relevant information can be extracted. High resolution DEMs from e.g. LiDAR are therefore more appropriate, but have disadvantages of being price-intensive, not always available and containing numerous anthropogenic overprinting structures. In contrast, medium resolution DEMs have the advantage of being globally and freely available (e.g. SRTM, ASTER GDEM, 2009) and most likely containing only natural topographic information. The disadvantage of a coarser resolution is potentially hindering extraction of small-scale topographical lineaments.

Despite the above-mentioned promising basis for lineament extraction, different authors point out critical aspects. Lineaments derived from elevation data could also have a non-tectonical origin (Arenas Abarca, 2006; Jordan and Schott, 2005). Reasons can be related to morphology and lithology causing identical linear topographic expressions that must be treated carefully.

The objective of this study is therefore to elaborate a robust method in order to access information on groundwater in remote and politically sensitive regions where data availability is scarce. We present a semi-automatic and transparent approach of extracting lineaments, which are evaluated in terms of hydrogeological significance and finally used to derive possible groundwater flow-paths. The method is applied exemplary along the western catchment of the Dead Sea (Israel/Palestine). In order to evaluate and validate our findings we intensively compare them to structural characteristics and groundwater modelling results of this area.

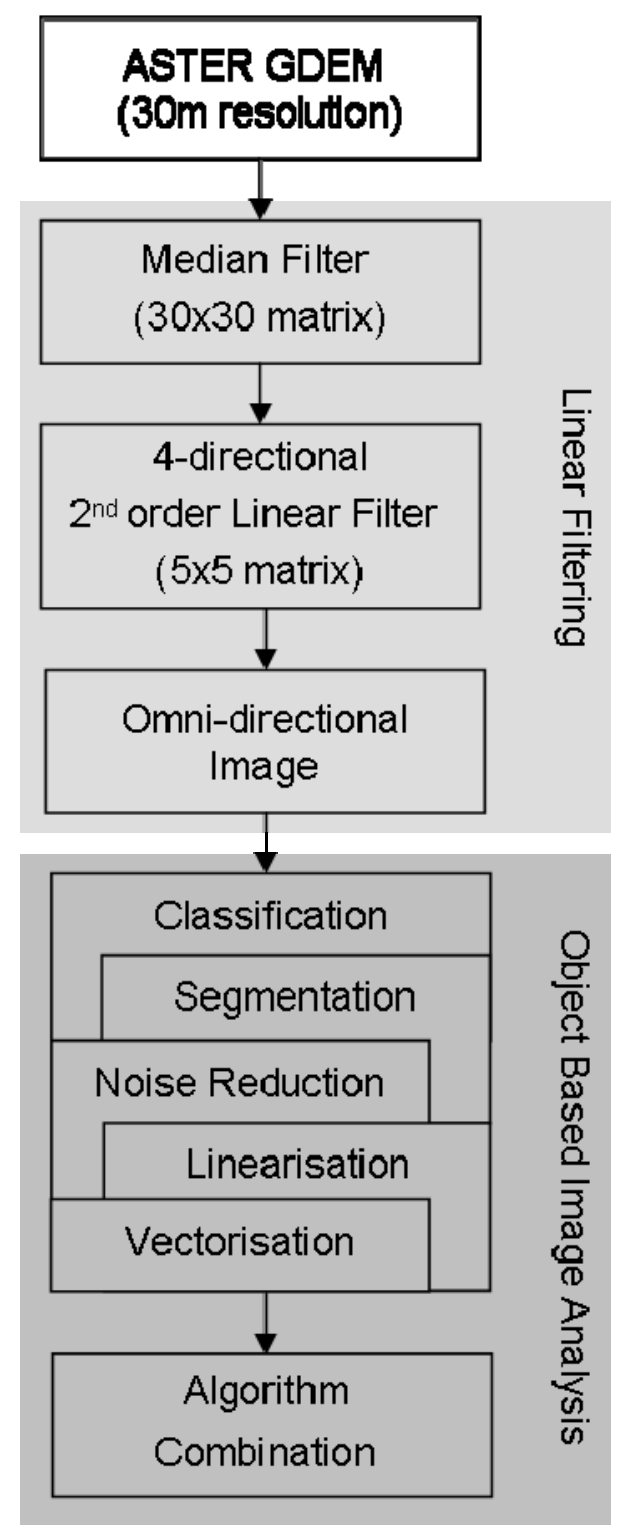

Fig. 1. Workflow of the applied methods for the semi-automatic extraction of lineaments.

\section{Extraction of lineaments}

\subsection{Pre-processing}

The study is based on the ASTER GDEM (ERSDAC, 2009) with a GSD of $30 \mathrm{~m}$, which is adequate for medium-scale studies (Abdullah et al., 2009; Hung, 2007) (Fig. 1). Since a validation report of this elevation product clearly states that it "does contain residual anomalies and artefacts (ASTER GDEM Validation Team: 19)" it is necessary to apply a smoothing filter before further analysis. Investigating different filter sizes revealed that artefacts are entirely removed by using filter sizes of $30 \times 30$ pixels. This filter size contains the risk of suppressing smaller structures with a pulse 

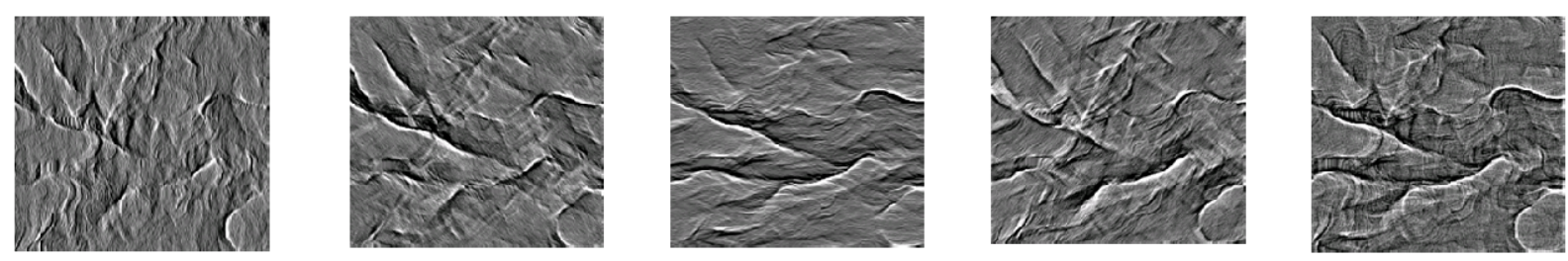

\begin{tabular}{|c|c|c|c|c|}
\hline-1 & -1 & 4 & -1 & -1 \\
\hline-2 & -2 & 8 & -2 & -2 \\
\hline-3 & -3 & 12 & -3 & -3 \\
\hline-2 & -2 & 8 & -2 & -2 \\
\hline-1 & -1 & 4 & -1 & -1 \\
\hline
\end{tabular}
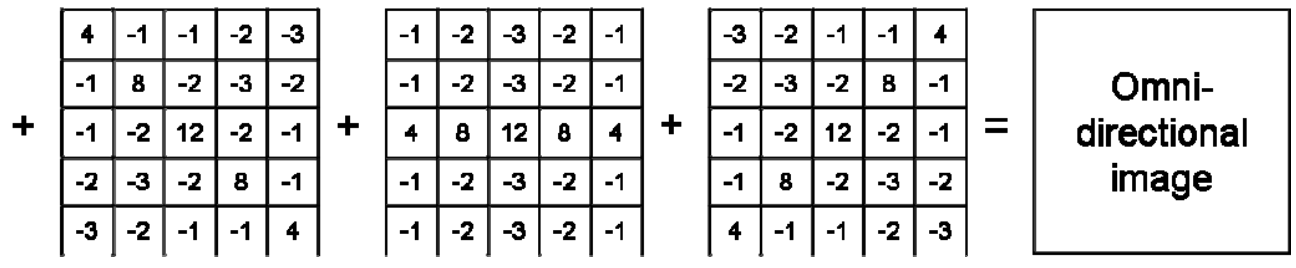

Fig. 2. Applied $5 \times 5$ 2nd order Laplacian linear filter on $30 \times 30$ median filtered ASTER GDEM and the result after combining all directional images to one omni-directional image keeping the maximum value of each pixel.

function having the size of less than one-half of the filter size (Pratt, 2007). However, the advantages outweigh the disadvantages as it eliminates artefacts inherited in the DEM that could not be eliminated with smaller filter sizes.

Another important decision is the type of smoothing filter. Following Arias-Castro and Donoho (2009) it is advisable to use Median filter since it preserves topographic structures like ridges, ramps, peaks and steps which usually have sizes above one-half of the matrix or do not represent a pulsefunction (Quackenbush, 2004; Yang and Huang, 1981). Using Mean or Gaussian filter that also eliminate artefacts and noise would not preserve edges in a comparable manner. This is especially true for areas where we would assume lowlevel noise, as it is the case in e.g. sparsely to non-forested areas. More information on smoothing filter and their effects can be found in Mather (2004).

After preparing the DEM, a set of 2nd order Laplacian linear filters in all main directions $(\mathrm{N} ; \mathrm{NW} ; \mathrm{W} ; \mathrm{SW})$ introduced by Pratt (2007) is applied using a $5 \times 5$ matrix to detect edges within the DEM (Fig. 2). Appropriate filter sizes can be determined by visually analyzing the smoothness/roughness of the respective study area. Chavez and Bauer (1982) defined several categories based on the topography where edge detection on very smooth surfaces should have a filter size of $9 \times 9$, whereas on rough surfaces a $3 \times 3$ filter size should be applied. The advantage of using 2 nd order filters is the accentuation of edges that mark a significant spatial change in the second derivative (Pratt, 2007; Wladis, 1999). The result enhances all edges that are defined by a series of adjacent pixels of similar high value, which represent topographic features. Concluding the linear filtering step, all four directional images are analysed on a pixel-by-pixel basis and merged into one omni-directional image, keeping only the maximum value of each pixel (Fig. 2).

\subsection{Object-Based Image Analysis}

The omni-directional image described above serves as basis for the object-based classification using Imagine Objective (ERDAS). Any supervised classification is defined by training pixels that determine the spectral range per class. Foody et al. (2006) suggested a minimum number of 30 training pixels per class in order to ensure an accurate classification result. We followed their recommendation and manually chose 30 training samples per class homogeneously distributed throughout the omni-directional image focussing on two classes: (1) adjacent pixels of high values representing edges and thus topographic features and (2) background pixels representing areas without edges. The classifier analyses each pixel value and compares it to the training samples creating a probability metric (range of 0 to 1 ) per pixel. As a result a probability image is created where high probability values represent an edge-class membership whereas low values represent the background-class. Those probability values form the basis to qualitatively and quantitatively define an adequate threshold that separates both classes during the following "threshold and clump" procedure.

Given the fact that the probability image strongly depends on the chosen training samples a uniformly applicable threshold cannot be defined. We suggest to iteratively applying different thresholds and comparing the result to the expected outcome. For the present study a threshold value of 0.8 represents the best result. During the "threshold and clump" procedure the probability image is converted into a binary image assigning values equal or above the threshold to 1 and below the threshold to 0 . The subsequent clumping analyses the contiguity in all directions and groups connected pixel with values of 1 to objects (ERDAS, 2008).

Due to topographical conditions and the classification process the objects partly contain boundary irregularities e.g. gaps within an object or nearby-objects having a Euclidean distance of only pixel. In order to concretize and 
simplify the neighbourhood connectivity and thus to enhance further processing it is necessary to clean those irregularities. Most suitable is the mathematical morphology closing, where a dilation operation is performed followed by an erosion operation. During the dilation objects are increased by one pixel on their boundaries. As a possible effect, gaps within the object or between near objects are closed (Costa and Starkey, 2001; Pratt, 2007). The concatenated erosion removes single not connected pixel. Concluding, almost explicitly connected pixels that represent discrete topographic edges are left.

The produced objects differ in pixel number from single pixel to large aggregates. Depending on the considered scale it is noteworthy to mention that objects of certain size (number of pixels) may not be relevant and thus can be excluded. Since we focus on a medium-scale where rather large structures are relevant, we excluded objects having less than 20 pixels using a size filter. The number of 20 pixels originates from the assumption that relevant tectonical or morphological structures have lengths of above $400 \mathrm{~m}$. Since most of the objects are composed of a minimum of three rows, a total length (longest object axis) of $300 \mathrm{~m}$ is expected, which is well below the length of relevant structures. Note that this step is not compulsory particularly if the focus were on the extraction of small-scale structures.

So far, objects are raster objects that are difficult to quantitatively compare to vector objects during further analysis. By applying the "centerline convert" algorithm the simplified raster-objects are thinned to lines representing the center or the longest axis of the object (ERDAS, 2008). During the concluding step extracted lines can be linked if certain criteria are fulfilled. Optional criteria include: maximum gaps between line-ends, minimum line lengths, minimum link length and a tolerance value. The way the parameters are chosen strongly depends on the objective of the study. If it is intended to obtain large connected structures minimum maximum gap between line-ends should have high values to be able to link lines with larger gaps. Small-scale investigation should use low values of minimum output-lengths and maximum gap between line-ends. All parameter options are subjective and can significantly influence the result, which intensifies the need to properly set every parameter based on the respective objective. For the present study the focus is on the detection of structures with lengths of above $400 \mathrm{~m}$ and furthermore to use a minimum of interpolation in between detected structures. The synergetic effect of both criteria represents most likely the closest possible image to reality. The defined parameter for the present study therefore included: maximum gaps between line-ends $(300 \mathrm{~m})$, minimum output-lengths $(390 \mathrm{~m})$, minimum link-length $(210 \mathrm{~m})$ and tolerance $(30 \mathrm{~m})$. The output is a map that displays linear structures with length and orientation-metrics derived from elevation data that are called lineaments from hereon, based on the terminology of O'Leary et al. (1976).
Table 1. Chosen parameter for LINE algorithm.

\begin{tabular}{lll}
\hline RADI & Filter radius & 60 \\
\hline GTHR & Edge Gradient Threshold & 10 \\
LTHR & Curve Length Threshold & 60 \\
FTHR & Line Fitting Error Threshold & 3 \\
ATHR & Angular Difference Threshold & 15 \\
DTHR & Linking Distance Threshold & 10 \\
\hline
\end{tabular}

\subsection{Combination with PCI Line algorithm}

PCI LINE (PCI Geomatics) offers an alternative, widely applied and robust method to automatically extract lineaments. The disadvantage using this method lies in the fact that six parameters can be changed, but only the final result can be visualized. Any intermediate-result, which would help the user to adapt only certain parameters, remains in the internal memory. To gain reliable result the user needs to have some experience. Thus, although lineaments extracted using the object-based approach generally compare favourably and step-wise reproducible to those produced by PCI Line, both methods are integrated for completeness.

The basic approach of PCI Line is similar to the objectbased approach. The only difference is the fact that the PCI Line bases on the robust Canny edge detection algorithm. This algorithm filters the DEM with a Gaussian filter, which depends on the chosen moving window size (RADI) from which the gradient is subsequently computed. The pixels that do not represent a local maximum are suppressed. The next step binarizes the image based on a threshold value GTHR, and a thinning algorithm is applied. A vectorization to extract lines ends the process. Defining parameters include LTHR for a specified minimum pixel size, FTHR for fitting lines and ATHR and DTHR for linking lines over a specified distance and angular difference (Kocal et al., 2004). Based on this knowledge and the chosen parameters (Table 1), we expect to have small differences but general agreement between the results.

By comparing the results it could clearly be seen that both methods produce similar results, yet some larger lineaments extracted by the PCI Line are not detected using the objectbased approach. Vice-versa, the PCI Line algorithm does not detect smaller lineaments that are detected by the objectbased approach.

To obtain a complete and complementary lineament map we combine both lineament results, where identical lineaments detected by both approaches are singularized during a GIS analysis. The focus is on smaller lineaments as they represent the objective topographic differences to a high degree (Fig. 3). 


\section{Differentiation of lineaments}

As briefly mentioned above, lineaments directly derived from medium resolution elevation data usually rely solely on natural topographical information. This fact, together with the smoothing of the DEM in the first processing step, ensures that man-made features such as streets, canals, field boundaries etc. are not contained.

Although lineaments are derived only based on natural topographical features and are an indicator of groundwater flow-paths, their hydrogeological importance needs to be evaluated as suggested by Jordan et al. (2005) and Sander (2007). This step is essential in order to reliably decide whether lineaments have significance in terms of hydrogeology or reflect irrelevant topographical features. Sander (2007) suggests using ancillary data, such as information on topography/geology and drainage to group lineaments into classes. The reason for differentiating lays in the development of linear topographical structures (abrupt changes in topography). Those changes are not necessarily bound to tectonical processes only. Instead, erosion (aeolian/fluvial) and different resistivities of rocks can also cause similar linear expressions (Arenas Abarca, 2006; Jordan et al., 2005; Sander et al., 1997) but have less hydrogeological significance.

Since vegetation is not a factor in the present DEM-based case, we include drainage system information and additionally introduce geological maps to differentiate extracted lineaments into geological lineaments (true structural origin) and morphological lineaments (mainly morphological origin with possible structural background). We furthermore investigate the spatial relationship "distance to wells" to create an assessment criterion which quantitatively enables the user to even analyse lineament hydraulic significance. Based on all background information general groundwater flow-paths are derived.

\subsection{Drainage system}

Several software packages offer the possibility to calculate drainage systems. Important is the DEM as input parameter. In order to have a comparable basis it should be the same DEM used for lineament extraction. In the present study the eight-direction (D8) flow model incorporated in ArcMap 9.3 is applied. The output contains steadily changing orientations of drainage lines over pixel distances $(30 \mathrm{~m})$. This fact reduces the possibility to objectively compare the drainage system to the extracted lineaments in terms of orientation. To overcome this aspect we suggest generalizing the drainage vector lines over a span of $180 \mathrm{~m}$. The resulting vector layer contains rather straight lines but keeps the general orientation. The lines are composed of several segments created every time the drainage system changes the direction. Since the segments are of interest rather than the total line, it is necessary to first split the drainage lines at their nodes. Using this sequence ensures that a correct orientation and length per segment is assigned.

After preparing the drainage vector it is possible to automatically compare it to the extracted lineaments quantitatively based on three parameters: Euclidean distance between the two, length and orientation. By defining each parameter depending on the objective of the study the similarity between both can be automatically analysed and the influence from the drainage system onto the lineaments can be inferred. In case lineaments display similar orientations for a certain portion of their total length and are located close to the created drainage vector, lineaments are probably induced by the drainages system and have to be evaluated as morphological lineaments.

For the present study we use the "Near" function of ArcGIS 9.3 to calculate the Euclidean distance between both features. A $500 \mathrm{~m}$ distance is chosen where we assume an influence of drainage systems to extracted lineaments. This is strongly dependent on the study area. In the present case the study area displays a high relief-energy with deep V-shaped valleys and distances between valley depth-line and valley shoulders below $500 \mathrm{~m}$ (see Sect. 4). This number should be raised when rather flat areas are investigated or lowered when steep mountainous regions are of interest. Furthermore, to account for either generalization errors or slightly atypical shaped valleys we define (2) an angle difference of $\pm 20^{\circ}$ for at least $20 \%$ of the line segment to account for either generalization errors or slightly atypical shaped valleys. Both numbers are general numbers and most likely independent of scale or study area.

\subsection{Geological map}

Similar to the drainage system it is necessary to infer lithological boundaries contained in geological maps and compare them to lineaments. If available, digital geological maps have to be treated favourably as they guarantee an objective comparison and enable an identical analysis sequence as described in the section before. Analogous geological maps need to be scanned and co-referenced to the DEM before further analysis. Since digitizing is labour- and time-intensive, particularly for larger study areas, we suggest performing the comparison based on lineaments by creating a buffer around each. If a lithological boundary displays similar orientation and is located within the created buffer, most likely this lineament reflects the boundary and therefore has to be evaluated as morphological lineament.

For the present study we create a buffer of $300 \mathrm{~m}$ to each side of the lineament. This buffer dimension generally reflects the effect of lineaments induced by lithological boundaries independent of scale and landscape. 

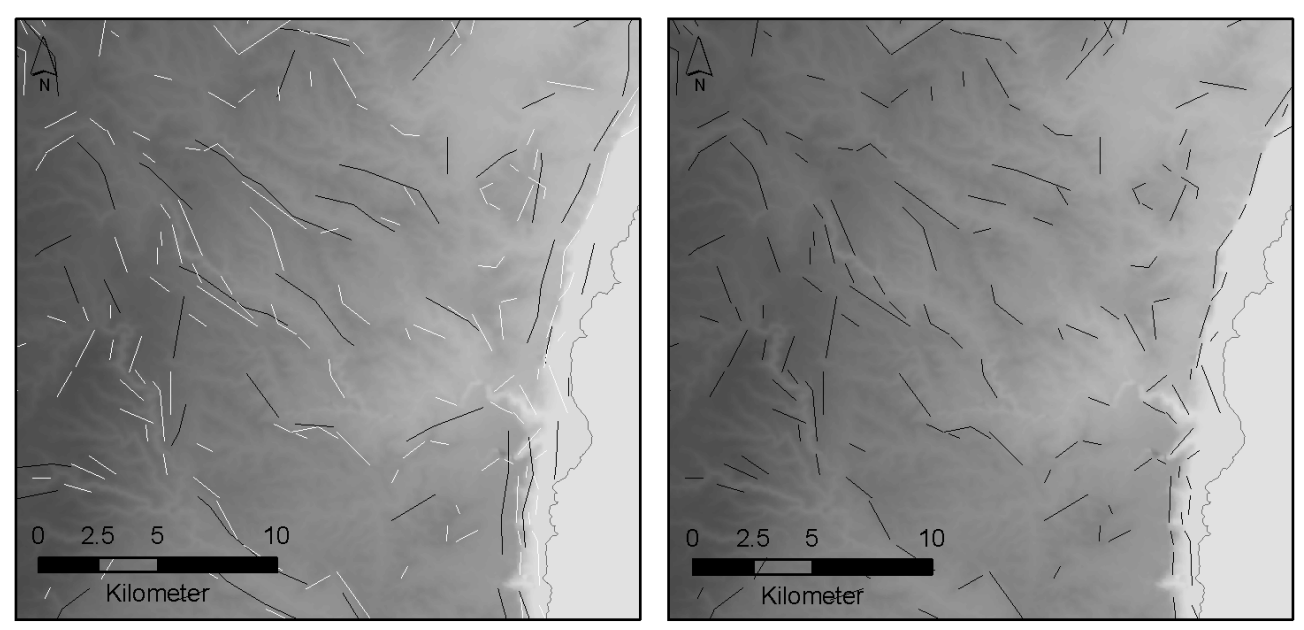

Fig. 3. Left figure shows a subset of the comparison of lineaments resulting from object-based classification (white lines) to lineaments obtained from PCI LINE algorithm (black lines) - right figure shows the same subset after singularization of identical results with respect to the object based result.

\subsection{Hydraulic significance and derivation of flow-paths}

After comparing lineaments to structural features and subsequently evaluating their geological significance, the hydraulic significance of lineaments must be assessed in order to gain information for the possibility of deriving groundwater flow-paths. Sander et al. (1997), Magowe and Carr (1999) and Henriksen (2006) showed that lineaments close to wells correlate with higher well yields. The distance between lineaments and wells, where a significant yield could be observed, varied between $250 \mathrm{~m}$ and $2000 \mathrm{~m}$. Since all mentioned studies explicitly explored well yields, it can be assumed that lineaments within similar distances to waterbearing wells also reflect probable hydraulic flow conditions. Thus, by calculating the Euclidean distance from each lineament to the nearest well location a simple quantitative metric is created to directly evaluate whether lineaments have a hydraulic significance or are rather randomly distributed.

Based on the evaluation of the hydraulic significance it is possible to infer general groundwater flow-paths under the co-consideration of topography and outlets (springs). Topography provides the general flow as water always tends towards the lowest point. In contrast, lineaments present a rather defined local flow direction characteristic whereas springs represent the final outlet of the system. Superimposing the lineaments on the 3-D-topography enables the user to derive most probable groundwater flow-paths by following the topography but preferring general orientation of lineaments. If done manually the result can be drawn with vector lines in GIS on the plotted 3-D surface. Nevertheless, an automation of the derivation is preferable as it is absolute objective.
For the present study we assumed all water wells (Fig. 4a) to produce water because only coordinates, name and well type were available. The same assumption applies for oil and gas wells based on Salhov et al. (1982) who describe water fluxes encountered during drilling. The data basis stems from Laronne Ben-Itzhak and Gvirtzman (2005), Mekorot Co. Ltd. (2007), Tel Aviv University (2007) for water wells and Fleischer and Varshavsky (2002), for exploration wells. Additionally, we define a second assessment criterion by introducing a parallel comparison to mapped faults of similar scale (structural map 1:200000). This is not obligatory for the derivation of flow-paths, but provides extra information on the degree of applicability of different sources for flow path derivation.

\section{Study area}

The study area represents the western subterranean catchment of the Dead Sea. The area is around $4160 \mathrm{~km}^{2}$ located between $34.73^{\circ} \mathrm{E}$ and $35.51^{\circ} \mathrm{E}$ and $30.83^{\circ} \mathrm{N}$ and $32.05^{\circ} \mathrm{N}$ (Lat/Lon WGS 84). It is comprised of major parts of the Judean Mountains in the west, the Negev desert in the south and the Dead Sea in the east (Fig. 4a) Within the area a topographical west-east altitude gradient of around $1000 \mathrm{~m}$ exists between the Judean Mountains and the brim located next to the Dead Sea and a further steep gradient of around $400 \mathrm{~m}$ from the brim to the current Dead Sea level of $-425 \mathrm{~m}$ (WGS84-EGM96), (own GPS measurements 03/2010).

The entire region is faulted and folded and since Eocene age finally shaped and modified by the strike slip movement of the Dead Sea transform (Garfunkel and Ben-Avraham, 2001), which is part of the Syrian-East African Rift system. 


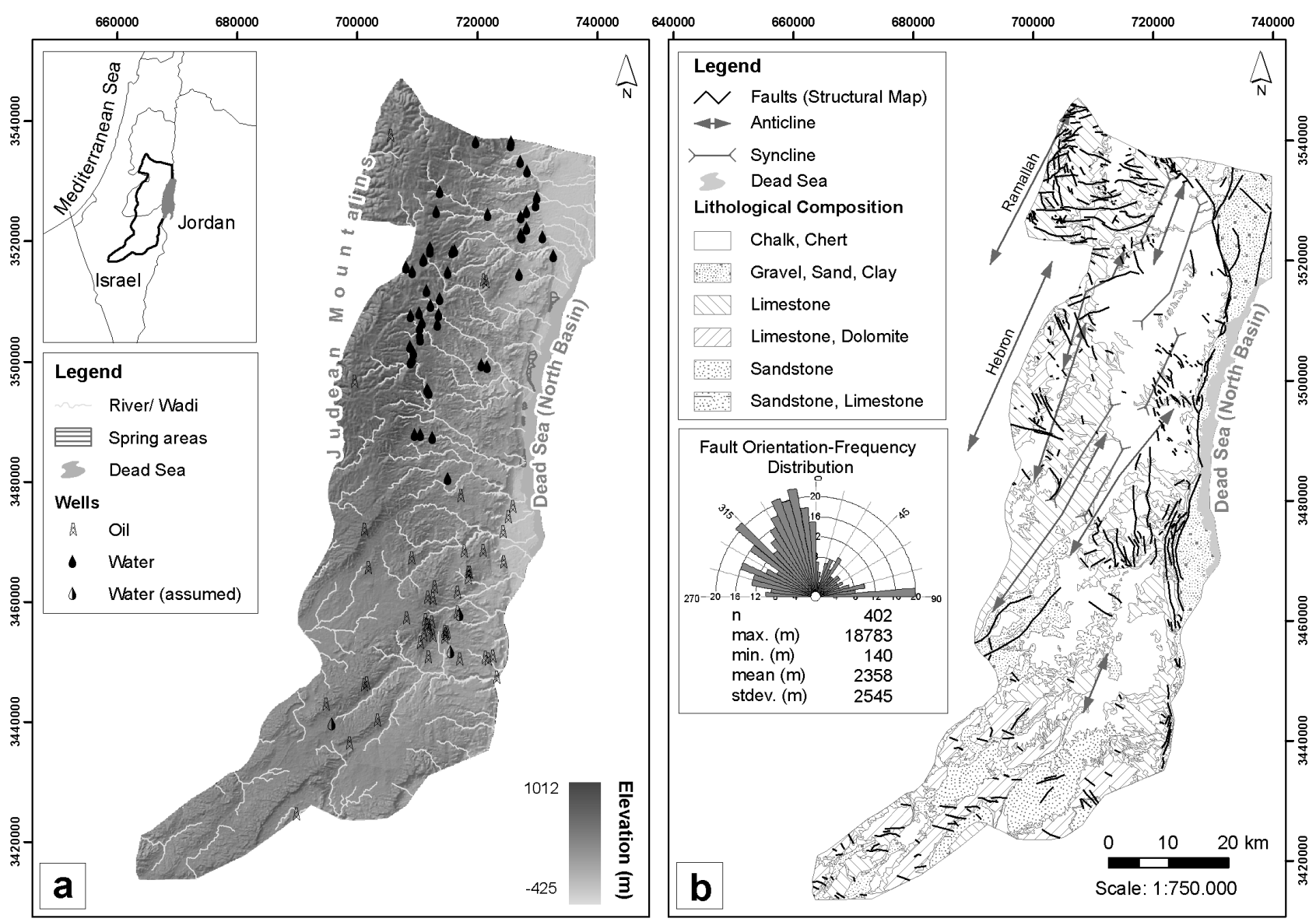

Fig. 4. Describes (a) topographical features of the study area ("Water wells assumed" refers to three water wells in the southern area taken from (Arad, 1966; Vengosh et al., 2007) and gives (b) a lithological and structural overview (Projection: UTM WGS 84 Zone $36^{\circ}$ N).

\subsection{Geology}

The geological formations of the western mountain range dip fairly eastwards. Lower Cretaceous Kurnub Group sandstones represent the base of the western escarpment and crop out in the southern study area. Above that, the 800-850 m thick hardly erodible limestones and dolomites of the Judea Group (Cenoman-Turon) are the predominant formation in the area (Fig. 4b) and constitutes the important Lower (LJGA) and Upper (U-JGA) Aquifers (Guttman, 2000). At the top of the range, the soft Mt. Scopus Group (SenonianPaleocene) with marl, chalk and clay occurs and reaches thickness of $100 \mathrm{~m}$ to $400 \mathrm{~m}$. These variations are controlled by anti- and synclinal structures of the compressional Syrian Arc phase (Flexer and Honigstein, 1984). The entire range is deeply cut by wadis, draining towards the Dead Sea. Products of those Plio-Holocene erosional processes are found within the wadis, their fans and along the Dead Sea coast being of gravel, sand, clay silt, marl and gypsum (Dead Sea Group).
On the western border of the study area, the Hebron anticline, which represents a main structural element, stretches with a SW-NE orientation (Fig. 4b), thus representing a main structural feature. A series of secondary mostly parallel asymmetric anticlines and synclines were developed among smaller fault systems observable throughout the entire area. The principal fault is represented by the western fault of the Dead Sea rhomb-shaped pull-apart basin. The dominating trends of all faults can be categorized into the following groups:

Faults of the Group A have an orientation of around $90^{\circ}(\mathrm{E}-\mathrm{W})$ and are mainly located in the north-western part of the study area. They may result from the Syrian-Arc deformation with maximum compressive stress trending NNW during Creataceous to Eocene ages (Eyal and Reches, 1983).

Group B is built by faults showing a main NNWSSE orientation $\left(330^{\circ}\right.$ to $\left.360^{\circ}\right)$ that are found from the north-western corner till the Dead Sea region, where their abundance increases significantly (Fig. 4b). These structures may be related to the Dead Sea strike-slip 
Table 2. Annual spring discharge of know spring locations within the study area (DS: Dead Sea shore).

\begin{tabular}{lrl}
\hline Spring & $\begin{array}{r}\text { Discharge } \\
\text { (MCM/a) }\end{array}$ & Source \\
\hline Quilt \& Fawwar & 5 & Guttman (2000) \\
Jericho Springs & 14 & Guttman (2000) \\
DS - Feschka & $80-85$ & Fink (1973), \\
& & Shachnai et al. (1983) \\
DS - Kane, Samar & $30-40$ & Greenboim (1992), \\
& & Guttman and Simon (1984) \\
DS - Kedem, Mazor & $4-5$ & Guttman and Simon (1984) \\
DS - En Gedi & $3-4$ & Laronne Ben-Itzhak and \\
& & Gvirtzman (2005) \\
\hline
\end{tabular}

transform, activated in the Miocene age (Garfunkel and Ben-Avraham, 1996, 2001). The major fault within that group is the N-S oriented western fault of the Dead Sea transform.

Group C faults, trending $310^{\circ}$ to $315^{\circ}$ (NW-SE) are the result of the compressional phase of the Syrian-Arc deformation during the Turonian age. Faults of that type are also described by Gilat (2005) as compressional features that follow Turonian-Senonian faults. The distribution within the study area is mainly in the westerly central part and in the north of the study area extending the western fault of the Dead Sea towards NW.

\subsection{Hydrogeology}

The major groundwater bearing strata are the Kurnub sandstone and the overlaying limy Judea Group with the two distinct aquifers. Both are hydraulically separated by the Bet Meir Formation, forming an aquiclude composed of clay, marl and chalk with varying thickness (Laronne Ben-Itzhak and Gvirtzman, 2005).

Hence, and as a result of the eastwards inclination of the rocks, the L-JGA becomes confined towards the Dead Sea while the U-JGA is entirely phreatic.

Where the separating aquicludes thin out locally and deep reaching faults exist, it is assumed that groundwater is able to percolate locally into adjoining aquifers. Consequently, groundwater-flow is defined either structurally or lithologically, meaning heterogeneities in transmissivity forces groundwater to bypass zones of low transmissivity (Guttman, 2000).

Precipitation amounts vary between $600 \mathrm{~mm} \mathrm{a}^{-1}$ in the highest elevated parts of the Judea Mountain range and around $100 \mathrm{~mm} \mathrm{a}^{-1}$ along the Dead Sea coast (Siebert, personal communication, 2010). However, the precipitation gradient does not decline homogeneously. From the Judean Mountains it slowly decreases towards the brim west of the Dead Sea. Between the brim and the graben the decrease

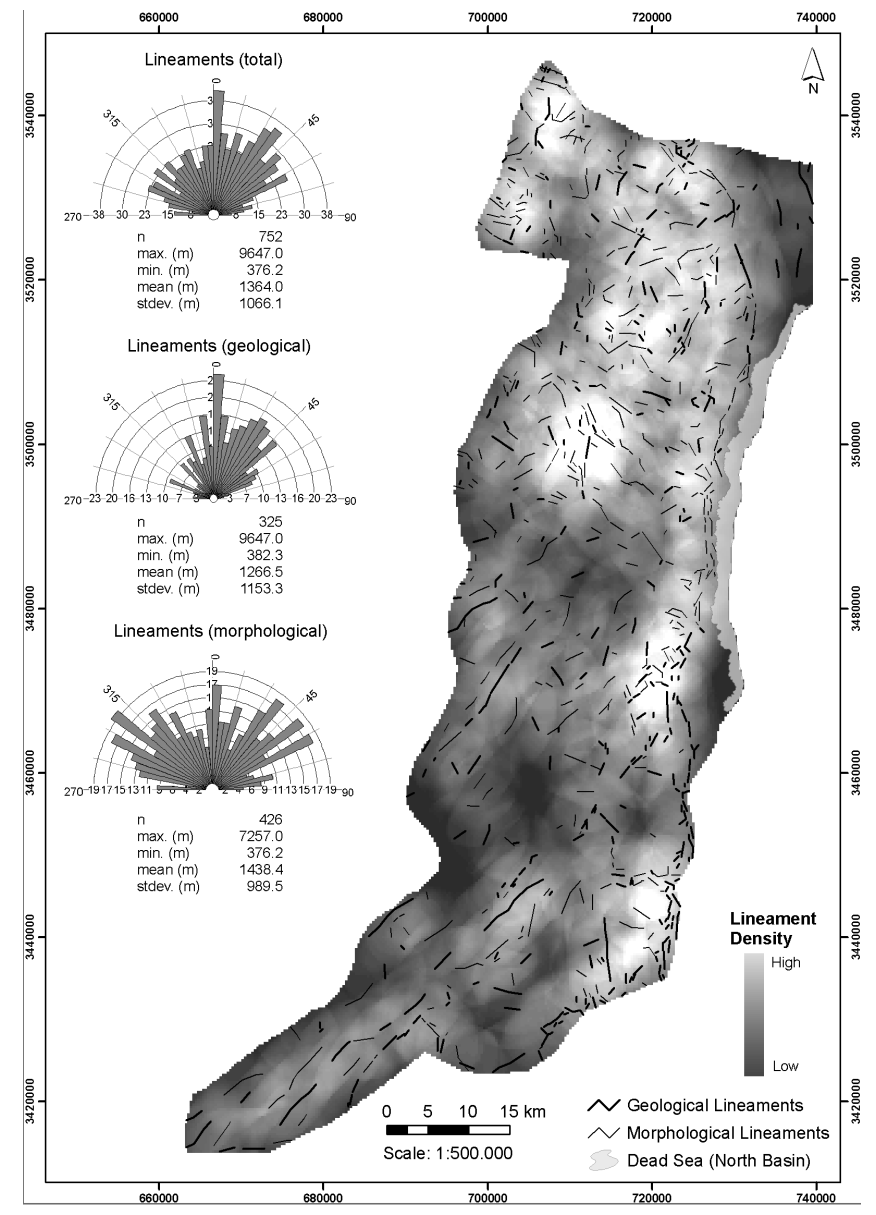

Fig. 5. Lineament map with rose diagrams for all lineaments and the differentiation of geological and morphological lineaments - in the background a calculated lineament density map with a $5 \mathrm{~km}$ radius is displayed (Projection: UTM WGS 84 Zone $36^{\circ} \mathrm{N}$ ).

is dramatic as a result of the important change in elevation. The highest amount of precipitation, which almost solely occurs between October and April, falls on outcroppings of the Judea Group aquifers. This aspect makes the west of the study area to the major region of recharge (Guttman, 2000).

The highest natural discharge of the aquifers in form of springs can be sorted by their location (Table 2). Approaching the Dead Sea, the spring discharges rise from low values at hinterland springs (Quilt, Jericho) to high values at the northern springs (Feshka, Kane and Samar) along the DS to decrease again at the southern springs (Kedem, Ein Gedi). Based on isotopic analysis it can be concluded that spring water is fed by the U-JGA and derived from precipitation in the recharge area (Siebert, personal communication, 2010). Only for the Kedem and Mazor springs a mixture of both Judea Group Aquifers is assumed (Guttman, 2000). 


\section{Results}

In total, 751 lineaments with lengths varying between $376 \mathrm{~m}$ and $9647 \mathrm{~m}$ were detected (Fig. 5). A lineament density (5 $\mathrm{km}$ search radius) exhibits a higher lineament density in the northern and north-western parts of the study area and along the western fault of the Dead Sea. It is apparent that lineaments within these high-density areas have smaller lengths compared to those in lower density regions.

The frequency-rose diagram (Fig. 5) illustrates the strike directions of all detected lineaments and additionally the differentiation of geological and morphological lineaments. The diagram of all lineaments (Lineaments total) displays the fact that two main strike directions are prominent. Most lineaments are oriented around $0-5^{\circ}$ and $30-40^{\circ}$, while a smaller amount strikes between both main trending directions. Equally noticeable is a similar frequency distribution of lineaments with an orientation between $290^{\circ}$ to $340^{\circ}$ and $45^{\circ}$ to $60^{\circ}$. Apparently, only few lineaments have an orientation of $90^{\circ}$ or $270^{\circ}$.

Partitioning the total lineaments in the detected geological and morphological lineaments reveals that geological lineaments match the main strike directions of the total lineaments almost explicitly. Small numbers represent orientations around $315^{\circ}$ to $350^{\circ}$ but none are around $90^{\circ}$ or $270^{\circ}$.

For the morphological lineaments three main strike directions are detected: (a) $295-330^{\circ}$ (b) $0-5^{\circ}$ (c) $35-65^{\circ}$. Most of the lineaments belonging to group $b$ are assigned to be of morphological origin due to their lithological-boundary characteristic (Fig. 6). A smaller number of lithologicalboundary induced lineaments display strike directions of

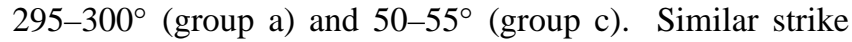
directions as group a and group c with an even higher frequency can be observed at the fluvial induced lineaments. Equally striking is the fact that less northern and only few western orientated lineaments are represented.

Considering the distance from lineaments to wells within the $500 \mathrm{~m}$ and $1000 \mathrm{~m}$ classes shows that the number of morphological lineaments $(n=26 / n=19)$ is above the number of geological lineaments $(n=15 / n=17)$ (Table 3$)$. The smallest distance of both lineament types is comparable within $1 \mathrm{~m}$. Within the $1500 \mathrm{~m}$ and the $3500 \mathrm{~m}$ class, the number of both types is steadily declining, reaching maximum distances of $3110 \mathrm{~m}$ and $2658 \mathrm{~m}$ respectively.

Therefore, a clear differentiation of lineament types based on the distance to wells cannot be established. Both types behave equally in distribution and very similarly in total number per class. Prior assumptions of morphological lineaments not having the same significance as geological lineaments concerning groundwater cannot be confirmed. Morphological lineaments generally exhibit better numbers with respect to minimum and mean distance as well as to the standard deviation. Moreover, based on the results, we calculated the number of geological and morphological lineaments, to- gether revealing that almost $75 \%$ of all lineaments are within a distance of $1000 \mathrm{~m}$ from a known well with a mean value of $879 \mathrm{~m}$.

In order to create a further assessment criterion, we calculated the distances to wells based on the mapped faults from the structural map. The general distribution reveals that more lineaments (10 to 21$)$ are contained within the closer distance classes $(\leq 2000 \mathrm{~m})$ whereas in greater distance classes $(>2000 \mathrm{~m})$ the number remains almost constant with 4 to 8 wells per class. The absolute distances of mapped faults to wells are between $13 \mathrm{~m}$ and $6767 \mathrm{~m}$. Although these numbers are similar to the previous ones from the "lineaments-to-wells-distances", it is diminished by taking the mean $(2140 \mathrm{~m})$ and the standard deviation $(1868 \mathrm{~m})$ values into account, which differ strongly.

In summary, the detected lineaments appear to be a better indicator compared to mapped faults in terms of distance to wells. This is most strongly supported by the normal distribution of lineaments enclosing ca. $75 \%$ of all lineaments to be within $1000 \mathrm{~m}$ distance to wells. To achieve the same percentage for mapped faults, the related distance would be within the $3000 \mathrm{~m}$ class. It is also pronounced by comparing mean and standard deviation values which are three orders of magnitude smaller for the distance to wells from lineaments than from mapped faults.

\section{Discussion}

\subsection{Method}

The proposed semi-automatic method of deriving groundwater flow-paths based on extracted lineaments and auxiliary information contains several advantages. (1) The medium-resolution and freely available DEM minimizes efforts to clean non-natural features and requires no financial expanses. (2) Median-filtering outperforms other smoothing filter (e.g. Gaussian, Mean) in terms of edge-preserving. (3) 2nd order Laplace linear-filtering in all four directions even accentuates edges improving subsequent extraction. (4) Applying the object-based image analysis to trace and extract lineaments guarantees a high degree of control concerning the edge detection (5) Auxiliary information greatly assist in evaluating lineaments and provide the basis to derive groundwater flow-paths.

However, some points are critical. Before the supervised classification the location of training samples is user dependent and thus requires certain expert knowledge. To maintain objectivity it would be necessary to analyse whether a general threshold can be applied after the linear-filtering step and directly use the binarized image as input where boundary irregularities are cleaned. Another subjective-related step concerns the line-link parameters. Although parameter settings are study-specific defined, they depend on a priori knowledge on geology/hydrogeology. If set differently, resulting 


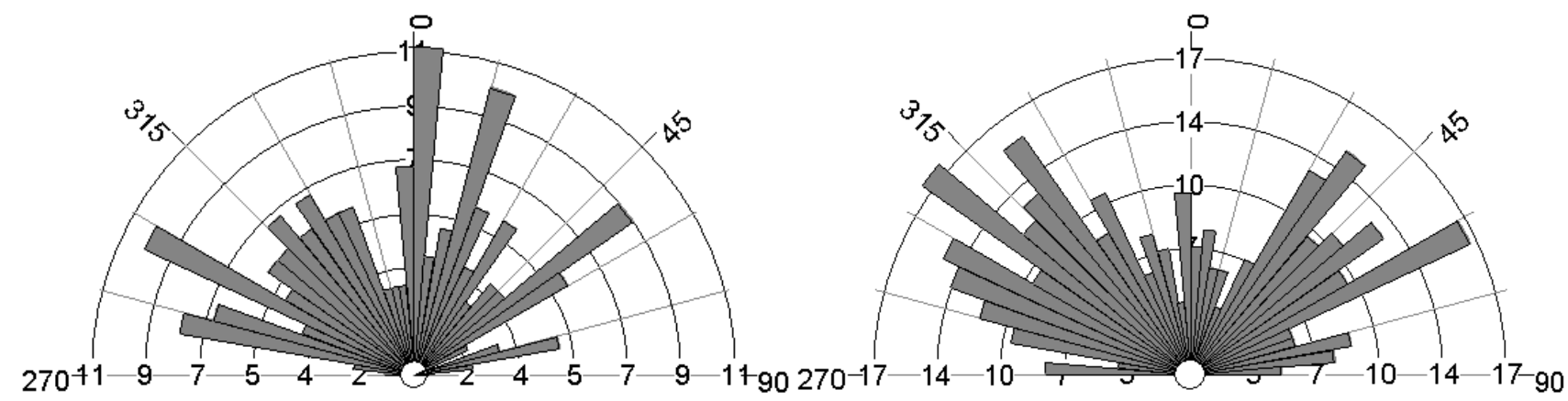

Fig. 6. Frequency-rose diagrams differentiating morphological lineaments to fluvial induced lineaments and lithological border induced lineaments (some lineaments are double-counted since they correspond to both characteristics).

Table 3. Comparison of Euclidean distances from wells towards the nearest feature (differentiated lineaments and faults contained in the structural map 1:200 000).

Distance of Diffe rentiated Lineaments to wells

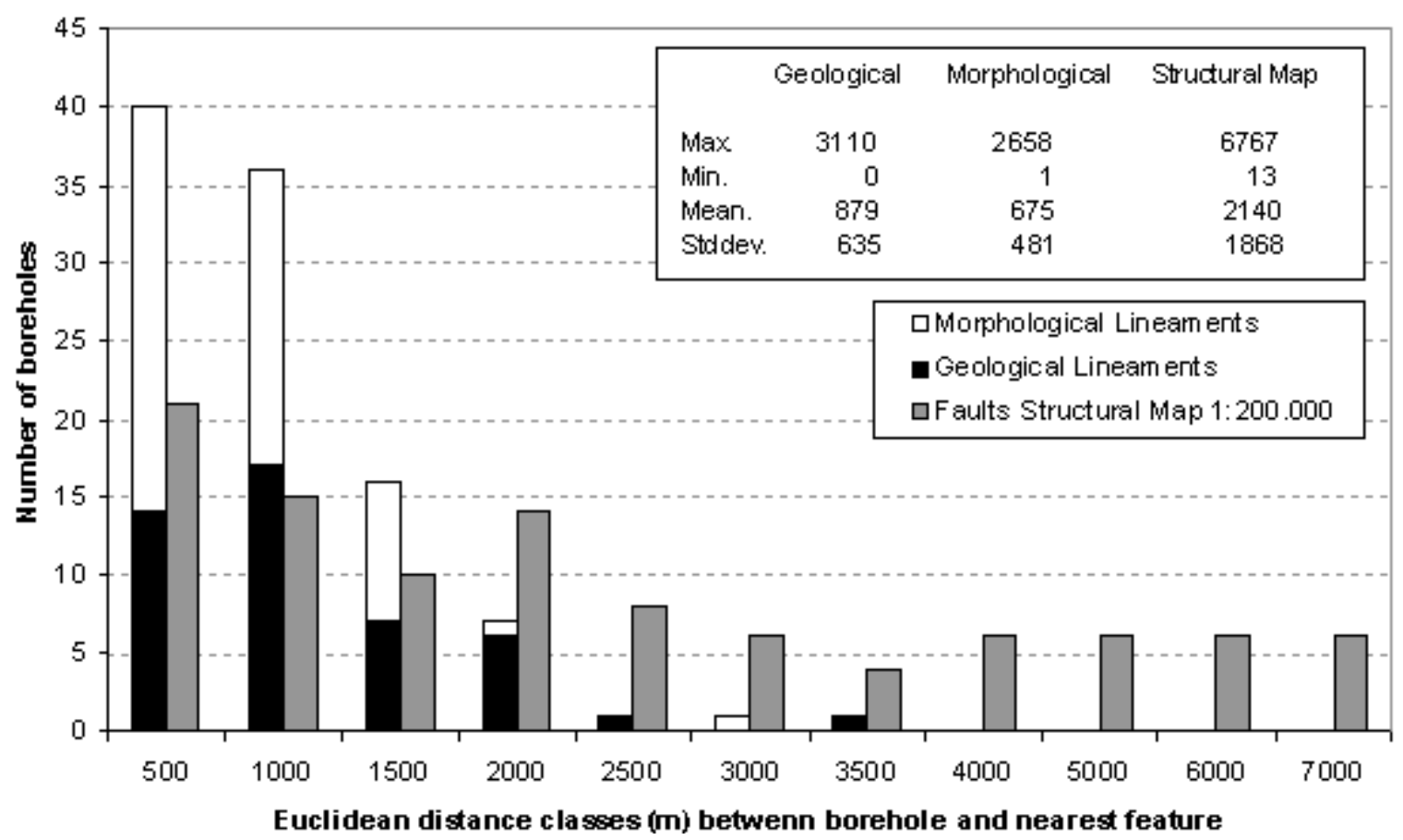

lineaments will as well be different varying in length and number. It is therefore of great importance to define those parameters depending on investigation-scale and -objective.

The derivation of flow-paths is based on well information. The better and reliable the information is, the better the evaluation of lineaments in terms of hydraulic significance. For the presented case study only well name, type and location are available implying an unknown error that could be omitted having more information.

\subsection{Site specific}

The detected northern $\left(0-5^{\circ}\right)$ as well as the north-eastern $\left(25-35^{\circ}\right)$ geological lineament orientations can be associated to the Syrian Arc system formed during the Turonian age (Flexer et al., 1989). Since the structural map only includes similar north-oriented fault directions, it must be assumed that the detected lineaments clearly describe the NE trending synclines, anticlines and monoclines structures with vertical displacements of up to $0.3 \mathrm{~km}$ (Gilat, 2005). We furthermore suppose that those lineament orientations equally represent faults that trend parallel to the hinge lines of the 
Syn-/Anticlines as shown by Flexer et al. (1989) for the Hebron anticline.

The cluster of morphological and particularly fluvial induced lineament directions around $45^{\circ}\left( \pm 15^{\circ}\right)$ suggests that the drainage system follows the NE trending syncline/anticline structures. The second cluster around $315^{\circ}\left( \pm 30^{\circ}\right)$ that also matches structural map fault orientations possibly originates from small NW trending faults. Those structures branch from the western Dead Sea fault partly following older Turonian-Senonian faults (Ginat et al., 1998). Those assumptions are supported by studies by Freund et al. (1968); Kafri and Heimann (1994) and Matmon et al. (1999), who proved the adjustment of the drainage system to morpho-tectonic features in the study area. The northern-oriented $\left(0-5^{\circ}\right)$ morphological lineaments explicitly stem from lithological edges and align along the western fault of the Dead Sea, most likely relating them to the Dead Sea stress field.

The $90^{\circ}$ lineament orientation was largely absent, possibly due to the fact that the Syrian Arc stress field related strike directions have been superimposed and/or displaced by younger movements (Gilat, 2005) evoking smaller structures that were either already included in the explanation or could not be detected. The remarkably well-matching orientations of lineaments and faults suggest a strong correlation among both. Based on the fact that faults have hydrogeologic significance by either hindering (compression/mineralized) or improving groundwater flow (extensional), this implicitly also accounts for lineaments within the study area.

Taking the distance analysis into consideration, which indicates that almost $75 \%$ of all detected lineaments are within $1000 \mathrm{~m}$ to the nearest well, we propose that the extracted lineaments do strongly have a hydrogeological significance. This also corresponds to findings of Sander et al. (1997), Magowe and Carr (1999) and Henriksen (2006). Therefore, this aspect enables us to derive general groundwater flow-paths.

Hence, taking the lineament importance for groundwater flow into account, together with elevation information and known spring areas along the Dead Sea (outlets), we suggest possible groundwater flow-paths (Fig. 7)

The flow-paths derived clearly exhibit a general E-W or SW-NE flow from the recharge areas in the western and the south-western part of the study area towards four main spring areas at the Dead Sea. The flow-paths in the northern part derive from the Ramallah anticline. They turn southward as they reach the western fault of the Dead Sea basin oriented NW in this region. There are most likely also flow-paths coming from the northern part of the Hebron anticline that have an E-NE trend. Both flow-paths merge and feed the Ein Feshka spring area.

Those flow-paths, together with the catchment size and the precipitation amount in the recharge area, lead to the high discharge for the Ein Feshka spring. The southwardlocated spring areas Kane, Samar and Darga exhibit similar

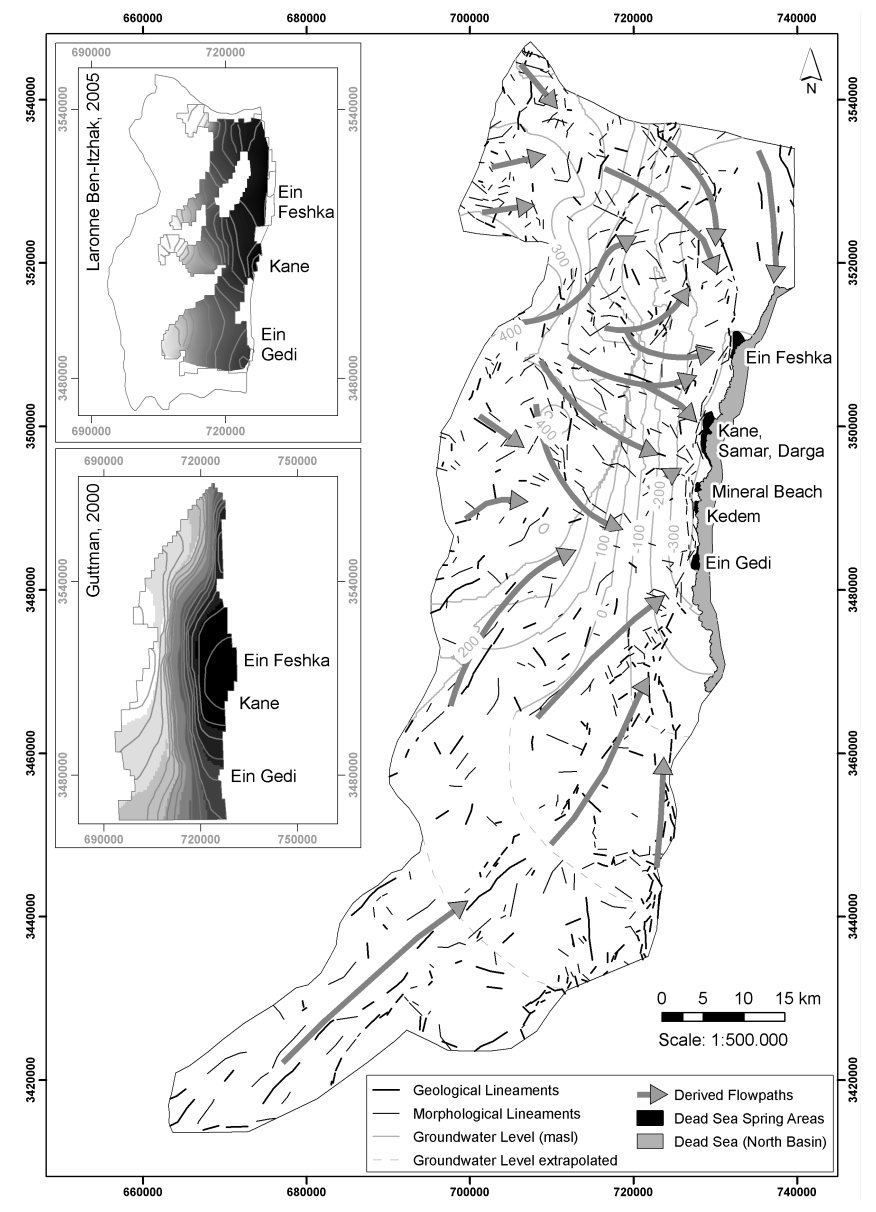

Fig. 7. Derived groundwater flow-paths based on lineament map, altitude and Dead Sea spring locations - for comparison the modelling results of (Guttman, 2000) and (Laronne Ben-Itzhak and Gvirtzman, 2005) and the groundwater level contour map are added (Groundwater level extrapolated refers to the insecurity of only three water wells in the southern area taken from Arad, 1966; Vengosh et al., 2007) (Projection: UTM WGS 84 Zone $36^{\circ} \mathrm{N}$ ).

characteristics. These areas are mainly fed by groundwater that follows ESE oriented flow-paths and partly NE trending groundwater, which most likely flows only towards the Darga springs. The catchment is smaller, thus reducing the potential amount of produced recharge which de-facto results in less discharge.

The groundwater that feeds the Ein Gedi spring area can be divided in two main flow-paths. The NE-trending flowpath is the longest of all flow-paths in the area but presumably bears only a small amount of water as the precipitation in the south-western area does not exceed an average of $220 \mathrm{~mm} \mathrm{a}^{-1}$ and is associated with high evaporation (Diskin, 1970). ESE-trending flow-paths with recharge areas in the Judean-Mountains with annually $600 \mathrm{~mm}$ of precipitation are rather significant. Taking those facts into account, with respect to the number of lineaments and in particular the 
overall trend towards Ein Gedi spring area, suggests a higher amount of flow and discharge than has been reported so far.

Based on the lineament map, the spring area around Mineral Beach and Kedem probably receives a very small amount of groundwater as only three lineaments are nearby and oriented towards that area. This could be due to the fact that these springs are fed by the deeper L-JGA, resulting in thermal springs with higher mineral concentrations (Guttman, 2000; Gvirtzman et al., 1997).

Since structures related to the deeper L-JGA could not be found, this appears to be the boundary condition for the lineament analysis. Thus, based on the lineament analysis, it is assumed that only flow-paths of the U-JGA can be derived from the lineament analysis and that only the structural developments of according Turonian to Pliocene ages are reflected. This assumption is partly underlined by Gilat (2005) who describes mega-lineaments visible on satellite images as reflections of Late Miocene-Pliocene structural developments.

What remains unclear is the hydraulic potential of single lineaments. Anisimova and Koronovsky (2007) describe lineaments as permeable for fluids in general. However, in the central and northern part of the study area, Ilani et al. (1988) pointed out that in carbonate rocks of the Cretaceous Judea Group along structural lineaments with E-W orientation and NE-trending monoclines iron mineralization and dolomitization occurred, thus inhibiting fluid flow. Similar processes could also characterize other lineaments with different orientations in the study area. Another aspect incorporates reverse faults mentioned before (Eyal and Reches, 1983; Flexer et al., 1989), although different hydraulic rock characteristics could possibly counteract on each other, hindering fluid flow as well. These aspects should be further investigated, if it is intended to prove hydraulic significance of individual lineaments.

Taking into account that limitations exist, the produced flow-path map are in good agreement with existing groundwater flow models (Guttman, 2000; Laronne Ben-Itzhak and Gvirtzman, 2005). Additionally, an interpolated contour map of the groundwater level based on well data (Fig. 7) underlines the derived flow-paths in the general flow and in complex sub-regions with varying flow directions in the northwest and west. Thus, based on these correlations it can be inferred that the flow-path map is valid.

\section{Conclusions}

In terms of efficient large-scale groundwater mapping the usage of remote sensing data, specifically of DEMs is apparent and can successfully be used to detect lineaments as indicators for hydraulic flow conditions.

In addition to efficiency, objectivity and transparency are eminent for reproduction. Applying the proposed semiautomatic approach using the ASTER GDEM and a combined linear filtering and object based classification approach fulfils all aspects. The linear filtering step exclusively relies on matrix based algorithms, whereas the object-based classification with Imagine Objective (ERDAS) needs only small adjustments during the process. Combining the lineament result with the similar automatic extraction algorithm LINE produces a lineament map that can be evaluated as objective and efficient.

Classifying and interpreting the result using ancillary information as suggested by Sander (2007) helps to understand the hydrogeological and hydraulic significance of each lineament and enables the authors to derive groundwater flowpaths. Based on this analysis, we concluded that:

- Detected lineaments within the study area have strong correlation with hydrogeologically relevant structural features since lineament orientations match remarkably well either Syrian Arc or Dead Sea Stress field related structural features that mainly have hydro-geological significance.

- It was shown that $75 \%$ of all lineaments, independent of lineament type, are located within a Euclidean distance of $1000 \mathrm{~m}$ to the nearest well. This implies that a high number of lineaments possess groundwater significance.

- Taking both points into account, it was suggested that together with an elevation map and the locations of spring areas the lineament map is appropriate to derive possible groundwater flow-paths. Compared results obtained from groundwater modelling of Guttman (2000) and Gvirtzman et al. (1997) which are based on water level data of wells reveal a good agreement. In return, this suggests that the delineated flow-paths from the lineament map are valid.

These results also show the applicability of the semiautomatic extraction method presented to objectively delineate lineaments and subsequently derive groundwater flowpaths. Moreover, it can preferably be applied prior to field campaigns in order to choose suitable sampling sites. Another application option is in remote/critical regions with limited geological/structural map availability and well information to improve the knowledge on groundwater. The applied medium resolution DEM potentially neglects smaller features that would be contained in DEMs with higher resolution. However, main advantages are the global and free availability and the fact that less processing is needed since man-made features are not contained. Using auxiliary information helps to gain insights in the connection between lineaments and structural features and thus in hydrogeological relevance of lineaments. Nevertheless, even without auxiliary data on geology or wells the developed method can be transferred to other study sites as only the medium resolution DEM is sufficient to derive general groundwater flow-paths. In those cases, the result would have less informative value but still provide useful knowledge on groundwater. 
Acknowledgements. The study was carried out by the BMBF funded project SUMAR (grant code: 02WM0848). Moreover, Helmholtz Impulse and Networking Fund through Helmholtz Interdisciplinary Graduate School for Environmental Research (HIGRADE) supported this work. Additional acknowledgement is directed to Geosystems $\mathrm{GmbH}$ for kindly providing Imagine Objective. The authors are grateful to two anonymous reviewers for their helpful comments that significantly improved the manuscript.

Edited by: P. Passalacqua

\section{References}

Abdullah, A., Akhir, J. M., and Abdullah, I.: A comparison of Landsat TM and Spot data for lineament mapping in Hulu Lepar Area, Pahang, Malaysia, European Journal of Scientific Research, 34(3), 406-415, 2009.

Anisimova, O. and Koronovsky, N.: Lineaments in the central part of the Moscow Syneclise and their relations to faults in the basement, Geotectonics, 41(4), 315-332, 2007.

Arad, A.: Hydrogeochemistry of groundwater in Central Israel, International Association of Scientific Hydrology, Bulletin, 11(1), 122-146, 1966.

Arenas Abarca, M. A.: Lineament extraction from digital terrain models: case study San Antonio del Sur area, South Eastern Cuba, ITC, Enschede, 81 pp., 2006.

Argialas, D. P. and Mavrantza, O. D.: Comparison of edge detection and Hough Transform techniques for the extraction of geologic features, Proceedings of the XXth ISPRS Congress of the International Society of Photogrammetry and Remote Sensing, Istanbul, Turkey, 1682-1750, 2004.

Arias-Castro, E. and Donoho, D. L.: Does Median Filtering Truly Preserve Edges Better Than Linear Filtering?, Annals of Statistics, 37(3), 1172-1206, 2009.

ASTER GDEM Validation Team: ASTER Global DEM Validation - Summary Report, METI \& NASA, 28, 2009.

Chavez Jr, P. and Bauer, B.: An automatic optimum kernel-size selection technique for edge enhancement, Remote Sens. Environ., 12(1), 23-38, 1982.

Costa, R. D. d. and Starkey, J.: PhotoLin: a program to identify and analyze linear structures in aerial photographs, satellite images and maps, Comput. Geosci., 27(5), 527-534, 2001.

Dinger, J. S., Andrews, R. E., Wunsch, D. R., and Dunno, G. A.: Remote sensing and field techniques to locate fracture zones for highly-yield water wells in the Appalachian Plateau, Kentucky, Proceedings of the National Ground Water Association Fractured-Rock Aquifer 2002 Conference, Denver, Colorado, 2002.

Diskin, M. H.: Factors affecting variations of mean annual rainfall in Israel, International Association of Scientific Hydrology, Bulletin, 15(4), 41-49, 1970.

ERDAS: Imagine Objective - User's Guide. Erdas Inc., Norcross, USA, 2008,

ERSDAC: ASTER GDEM is a product of METI and NASA, available at: http://www.ersdac.or.jp/GDEM/E/index.html, last access: 10 September 2009, 2009.

Eyal, Y. and Reches, Z. e.: Tectonic analysis of the Dead Sea Rift region since the Late-Creataceous based on meso-structures, Tectonics, 2(2), 167-185, 1983.
Fernandes, A. and Rudolph, D.: The influence of Cenozoic tectonics on the groundwater-production capacity of fractured zones: a case study in Sao Paulo, Brazil, Hydrogeol. J., 9(2), 151-167, 2001.

Fink, M.: Possibilities for groundwater utilization in the Northwestern basin of the Dead Sea, TAHAL Consulting Engineers Ltd., 01/73/02, 1973 (in Hebrew).

Fitton, N. C. and Cox, S. J. D.: Optimising the application of the Hough transform for automatic feature extraction from geoscientific images, Comp. Geosci., 24(10), 933-951, 1998.

Flexer, A. and Honigstein, A.: The senonian succession in Israel Lithostratigraphy, biostratigraphy and sea level changes, Cretaceous Res., 5(4), 303-312, 1984.

Flexer, A., Gilat, A., Hirsch, F., Honigstein, A., Rosenfeld, A., and Rueffer, T.: Late Cretaceous evolution of the Judean Mountains as indicated by ostracodes, Terra Nova, 1(4), 349-358, 1989.

Fleischer, L. and Varshavsky, A.: A lithostratigraphic data base of oil and gas wells drilled in Israel, Geological Survey of Israel (GSI), Jerusalem, 2002.

Foody, G. M., Mathur, A., Sanchez-Hernandez, C., and Boyd, D. S.: Training set size requirements for the classification of a specific class, Remote Sens. Environ., 104(1), 1-14, 2006.

Freund, R., Zak, I. and Garfunkel, Z. W. I.: Age and rate of the sinistral movement along the Dead Sea Rift, Nature, 220(5164), 253-255, 1968.

Garfunkel, Z. and Ben-Avraham, Z.,: The structure of the Dead Sea basin, Tectonophys., 266, 155-176, 1996.

Garfunkel, Z. and Ben-Avraham, Z.,:Basins along the Dead Sea Transform, in: Peri-Tethyan Rift/Wrench Basins and Passive Margins,, edited by: Ziegler, P. A., Cavazza, W., Robertson, A. H. F., and Crasquin-Soleau, Mem. Mus. Natn. Hist. Nat., 186, 607-627, 2001.

Gilat, A.: Strike-slip faulting west of the Dead Sea Escarpment, in: Geological framework o the Levant, edited by: Hall, J. K., Krasheninnikov, V. A., Hirsch, F., Benjamini, C., and Flexer, A., Jerusalem, pp. 515-522, 2005.

Ginat, H., Enzel, Y., and Avni, Y.: Translocated Plio-Pleistocene drainage systems along the Arava fault of the Dead Sea transform, Tectonophysics, 284(1-2), 151-160, 1998.

Gloaguen, R., Marpu, P. R., and Niemeyer, I.: Automatic extraction of faults and fractal analysis from remote sensing data, Nonlin. Processes Geophys., 14(2), 131-138, 2007.

Greenboim, J.: Discharge measurements in the Tsukim Springs in 5-6.8.92. Israel Hydrological Service, Water Commission, 1992 (in Hebrew).

Guttman, Y.: Hydrogeology of the Eastern Aquifer in the Judea Hills and Jordan Valley, Mekorot, 2000.

Guttman J. and Simon E.: Hydrological study of the western Dead Sea shore. Stage 1, report by TAHAL Consulting Engineers Ltd., 1984 (in Hebrew).

Gvirtzman, H., Garven, G., and Gvirtzman, G.: Thermal anomalies associated with forced and free ground-water convection in the Dead Sea rift valley, Geol. Soc. Am. Bull., 109(9), 1167-1176, 1997.

Henriksen, H.: Fracture lineaments and their surroundings with respect to groundwater flow in the bedrock of Sunnfjord, Western Norway, Norwegian J. Geol., 86(4), 373-386, 2006.

Hobbs, W. H.: Lineaments of the Atlantic border region, Geol. Soc. Am. Bull., 15, 483-506, 1904. 
Hung, L. Q.: Integrated analysis of sub-tropical mountain Karst geohydrology in NW Vietnam by field and multisource remotely sensed data Vrije Universiteit, Brüssel, 2007.

Hung, L. Q., Batelaan, O., and De Smedt, F.: Lineament extraction and analysis, comparison of LANDSAT ETM and ASTER imagery. Case study: Suoimuoi tropical karst catchment, Vietnam, Remote Sensing for Environmental Monitoring, GIS Applications, and Geology V. SPIE, Brugge, Belgium, 59830T-12, 2005.

Ilani, S., Rosenthal, E., Kronfeld, J., and Flexer, A.: Epigenetic dolomitization and iron mineralization along faults and their possible relation to the paleohydrology of southern Israel, Appl. Geochem., 3(5), 487-498, 1988.

Jordan, G. and Schott, B.: Application of wavelet analysis to the study of spatial pattern of morphotectonic lineaments in digital terrain models, A case study, Remote Sens. Environ., 94(1), 31$38,2005$.

Jordan, G., Meijninger, B. M. L., Hinsbergen, D. J. J. v., Meulenkamp, J. E., and Dijk, P. M. v.: Extraction of morphotectonic features from DEMs: Development and applications for study areas in Hungary and NW Greece, Int. J. Appl. Earth Obs., 7(3), 163-182, 2005.

Kafri, U. and Heimann, A.: Reversal of the palaeodrainage system in the Sea of Galilee area as an indicator of the formation timing of the Dead Sea Rift valley base level in northern Israel, Palaeogeogr. Palaeocl., 109(1), 101-109, 1994.

Karnieli, A., Meisels, A., Fisher, L., and Arkin, Y.: Automatic extraction and evaluation of geological linear features from digital remote sensing data using a Hough transform, 62, American Society for Photogrammetry and Remote Sensing, Bethesda, MD, ETATS-UNIS, 1996.

Kocal, A., Duzgun, H. S., and Karpuz, C.: Discontinuity mapping with automatic lineament extraction from high resolution satellite imagery, ISPRS XX, Istanbul, 2004.

Koike, K., Nagano, S., and Ohmi, M.: Lineament analysis of satellite images using a Segment Tracing Algorithm (STA), Comput. Geosci., 21(9), 1091-1104, 1995.

Laronne Ben-Itzhak, L. and Gvirtzman, H.: Groundwater flow along and across structural folding: an example from the Judean Desert, Israel, J. Hydrol., 312(1-4), 51-69, 2005.

Magowe, M. and J. R. Carr: Relationship between lineaments and ground water occurrence in western Botswana., Ground Water, 37(2), 282-286, 1999.

Marpu, P. R., Niemeyer, I., Nussbaum, S., and Gloaguen, R.: A procedure for automatic object-based classification, in: ObjectBased Image Analysis, Springer, 169-184, 2008.

Mather, P. M.: Computer-processing of remotely-sensed images An introduction, West Sussex, UK, 324, 2004.

Matmon, A., Enzel, Y., Zilberman, E., and Heimann, A.: Late Pliocene and Pleistocene reversal of drainage systems in northern Israel: tectonic implications, Geomorphology, 28(1-2), 43-59,. 1999.

Mavrantza, O. D. and Argialas, D. P.: Object-oriented image analysis for the identification of geologic lineaments, International Archives of Photogrammetry, Remote Sensing and Spatial Information Sciences XXXVI (4/C42), 2006.
Meijerink, A. M. J., Bannert, D., Batelaan, O., Lubczynski, M. W., and Pointet, T.: Remote sensing applications to groundwater. IHP-VI series on groundwater, United Nations Educational, Scientific and Cultural Organization, Paris, 311 pp., 2007.

Mekorot Co. Ltd.: 9 Lincoln Street, POB 2012, Tel Aviv 61201, 2007.

Morris, K.: Using knowledge-base rules to map the three- dimensional nature of geological features, Photogramm. Eng. Rem. S., 57(9), 1209-1216,1991.

O'Leary, D. W., Friedman, J. D., and Pohn, H. A.: Lineament, linear, lineation: Some proposed new standards for old terms, Geol. Soc. Am. Bull., 87(10), 1463-1469, 1976.

Oguchi, T., Aoki, T., and Matsuta, N.: Identification of an active fault in the Japanese Alps from DEM-based hill shading, Comp. Geosci., 29(7), 885-891, 2003.

Philip, G.: Landsat Thematic Mapper data analysis for Quaternary tectonics in parts of the Doon valley, NW Himalaya, India, Int. J. Remote Sens., 17(1), 143-153, 1996.

Pratt, W.: Digital image processing, Wiley-Interscience, Los Altos, CA, 771 pp., 2007.

Quackenbush, L. J.: A review of techniques for extracting linear features from imagery, Photogramm. Eng. Rem. S., 70(12), 1383-1392, 2004.

Salhov, S., Schlein, N., and Croker, P. F.: Gurim 4 - Recommendation for drilling, 82/55, Geological Survey of Israel (GSI), Tel Aviv, 1982.

Salvi, S.: Analysis and interpretation of Landsat synthetic stereo pair for the detection of active fault zones in the Abruzzi region (Central Italy), Remote Sens. Environ., 53(3), 153-163, 1995.

Sander, P.: Lineaments in groundwater exploration: a review of applications and limitations, Hydrogeol. J., 15(1), 71-74, 2007.

Sander, P., Minor, T. B., and Chesley, M. M.: Ground-water exploration based on lineament analysis and reproducibility tests, Ground Water, 35(5), 7, 1997.

Shachnai, E., Miro, F., and Meiri, D.: Hydrogeological survey in Tsukim Springs. TAHAL Consulting Engineers Ltd, Tel Aviv, Report no. 01/83/98, p. 22, 1983 (in Hebrew).

Suzen, M. L. and Toprak, V.: Filtering of satellite images in geological lineament analyses: an application to a fault zone in Central Turkey, Int. J. Remote Sens., 19(6), 1101-1114, 1998.

Tel Aviv University: Dept. for Geophysics and Planetary Sciences, Tel Aviv University, POB 39040, Tel Aviv, 69978, 2007.

Vaz, D. A., Di Achille, G., Barata, M. T., and Alves, E. I.: Manual and automatic lineament mapping: Comparing results, Lunar and Planetary Science XXXIX, 2008.

Vengosh, A., Hening, S., Ganor, J., Mayer, B., Weyhenmeyer, C. E., Bullen, T. D., and Paytan, A.,: New isotopic ev- idence for the origin of groundwater from the Nubian Sandstone Aquifer in the Negev, Israel, Appl. Geochem., 22(5), 1052-1073, 2007.

Wladis, D.: Automatic lineament detection using Digital Elevation Models with second derivative filters, Photogramm. Eng. Rem. S., 65(4), 453-458, 1999.

Yang, G. J. and Huang, T. S.: The effect of median filtering on edge location estimation, Comput. Vision Graph., 15(3), 224245, 1981. 